\title{
When are fish sources vs. sinks of nutrients in lake ecosystems?
}

\author{
Michael J. Vanni, ${ }^{1,4}$ Gergely Boros, ${ }^{1,2}$ and Peter B. McIntyre ${ }^{3}$ \\ ${ }^{1}$ Department of Biology, Miami University, Oxford, Ohio 45056 USA \\ ${ }^{2}$ Balaton Limnological Institute Centre for Ecological Research, HAS H-8237, P.O. Box 35, Tihany, Hungary \\ ${ }^{3}$ Center for Limnology, University of Wisconsin, Madison, Wisconsin 53706 USA
}

\begin{abstract}
Animals can be important in nutrient cycling through a variety of direct and indirect pathways. A high biomass of animals often represents a large pool of nutrients, leading some ecologists to argue that animal assemblages can represent nutrient sinks within ecosystems. The role of animals as sources vs. sinks of nutrients has been debated particularly extensively for freshwater fishes. We argue that a large pool size does not equate to a nutrient sink; rather, animals can be nutrient sinks when their biomass increases, when emigration rates are high, and/or when nutrients in animal carcasses are not remineralized. To further explore these ideas, we use a simple model to evaluate the conditions under which fish are phosphorus (P) sources or sinks at the ecosystem (lake) level, and at the habitat level (benthic and water column habitats). Our simulations suggest that, under most conditions, fish are sinks for benthic $\mathrm{P}$ but are net $\mathrm{P}$ sources to the water column. However, $\mathrm{P}$ source and sink strengths depend on fish feeding habits (proportion of $\mathrm{P}$ consumed from the benthos and water column), migration patterns, and especially the fate of carcass P. Of particular importance is the rate at which carcasses are mineralized and the relative importance of benthic vs. pelagic primary producers in taking up mineralized $\mathrm{P}$ (and excreted P). Higher proportional uptake of $\mathrm{P}$ by benthic primary producers increases the likelihood that fish are sinks for water column P. Carcass bones and scales are relatively recalcitrant and can represent a $\mathrm{P}$ sink even if fish biomass does not change over time. Thus, there is a need for better documentation of the fraction of carcass $\mathrm{P}$ that is remineralized, and the fate of this $\mathrm{P}$, under natural conditions. We urge a more holistic perspective regarding the role of animals in nutrient cycling, with a focus on quantifying the rates at which animals consume, store, release, and transport nutrients under various conditions.
\end{abstract}

Key words: animal-mediated nutrient cycling; bones; decomposition; fish; lake; mineralization; nutrient sink; phosphorus.

\section{INTRODUCTION}

Animals are increasingly recognized as important in nutrient cycling (Vanni 2002, Estes et al. 2011). Direct nutrient fluxes through animals can be significant when their biomass is high (McNaughton et al. 1997, Vanni 2002, McIntyre et al. 2008), and animals can move nutrients between ecosystems (e.g., Janetski et al. 2009). In addition, animals have many indirect effects on nutrient cycling, arising from their regulation of food webs and consequent effects on nutrient fluxes (Vanni 2002, Schmitz et al. 2010). Finally, animal biomass may

Manuscript received 11 September 2012; revised 4 March 2013; accepted 3 April 2013. Corresponding Editor: H. Hillebrand.

${ }^{4}$ E-mail: vannimj@miamioh.edu represent a large nutrient pool that can be very stable in long-lived species (Kitchell et al. 1975, 1979, Griffiths 2006, Frank 2008).

The potential for animal biomass to represent a large nutrient pool is enhanced by the fact that animal tissues generally have high nutrient concentrations compared to plants and many abiotic pools (Sterner and Elser 2002). Thus, animal biomass represents a locus where nutrients are concentrated (Kitchell et al. 1975), especially where animal biomass is relatively high (e.g., many aquatic ecosystems, grasslands, and savannas). Moreover, animals collectively feed on an enormous diversity of food sources, such that most other ecosystem nutrient pools are directly or indirectly accessed by animals through the food web. For these reasons, perhaps it is intuitive to suspect that animals are nutrient sinks (e.g., Sereda et al. 2008). However, the extent to which animal biomass (or 
any other pool) is a nutrient sink depends critically on temporal changes in pool size as well as the pool size itself. Vitousek's (2004:148) definition is apt:

Sinks are pools of nutrients that accumulate over time; in effect, nutrients in the sink are removed from circulation in the ecosystem as a whole for as long as that pool remains intact.

Thus, a large pool size does not necessarily equate to a sink. Rather, a pool is a sink only if both the fluxes of nutrients into the pool exceed fluxes out of the pool over a specified time, and these nutrients are rendered unavailable to organisms outside of that pool. In addition, when evaluating whether animal biomass is a nutrient source or sink, it is imperative to explicitly specify the spatial and temporal scales of interest. This is because animals may be a nutrient source to one habitat and a sink for another habitat within an ecosystem. For example, insects that feed on tree leaves but deposit frass to soil may be sinks for the aboveground habitat, but a source for the soil food web. Similarly, animals can be sinks for some biota but not others, e.g., nutrients incorporated into herbivores may be a sink for plants but not for carnivores. Furthermore, all of these examples depend on temporal scale. For example, nutrients in animal biomass may be a sink in the short term, but after the animals die and decompose, their tissue nutrients may become available.

In aquatic ecosystems, excretion of wastes by animals can be an important source of nutrients to primary producers and bacteria (e.g., Grimm 1988, Vanni et al. 2006, McIntyre et al. 2008). However, some ecologists have suggested or concluded that long-lived aquatic animals with persistently high biomass, namely fish, are nutrient sinks rather than sources (Griffiths 2006, Sereda et al. 2008, Sereda and Hudson 2010). These arguments are based largely on the observation that fish biomass is a large yet stable nutrient pool, as originally noted by Steele (1974) and Kitchell et al. (1975, 1979). However, as for any animal population, the extent to which fish are nutrient sources or sinks depends on spatial and temporal scales. For example, if fish consume resources from the benthos and excrete nutrients into the water, they may be nutrient sinks for the benthos but sources to the water column (e.g., Vanni et al. 2006). However, if fish sequester zooplankton-derived nutrients in their bodies or deliver them to the benthos, they may be sinks for the water column habitat. Similar logic applies in the temporal domain. For example, benthivores may be short-term sinks for benthic nutrients, but upon death and decomposition their body nutrients may be taken up by benthic producers; in this case these fish are not longterm benthic sinks.

We have two main goals in this paper. First, we wish to clarify conceptual issues regarding the definition of a nutrient sink in the context of animal populations, and discuss criteria for evaluating whether animals are nutrient sources or sinks. Second, we use a simple model to evaluate the conditions under which fish are nutrient sinks or sources both at the habitat level (benthos and water column) and the ecosystem level (whole lake). Fish are an appropriate model taxon for these analyses because they are long lived, have high tissue nutrient concentrations, and have been suggested to be nutrient sinks (Griffiths 2006, Sereda et al. 2008). Our model is designed specifically for lakes, primarily because the information we need to construct such a model is more available for lakes than for rivers or marine systems. However, the concepts we discuss and our modeling approach can be applied to any animal population or assemblage.

\section{Conceptual Issues}

At the ecosystem level, there are three general ways in which animals can be nutrient sinks (Fig. 1). First, their biomass can increase over time within the ecosystem, i.e., the flux of nutrients into live biomass exceeds the flux out of live biomass (Fig. 1A). This occurs if growth plus reproduction (at the population level) exceeds mortality. Such an increase might occur seasonally, for example, during periods of young-of-year fish recruitment, though seasonal decreases may be equally common (e.g., high mortality and negligible growth in winter). A multiyear increase in biomass may also occur in a population that is recently stocked or recovering from a high-mortality event.

A second means by which animals can be an ecosystem-level sink is if emigration from the ecosystem exceeds immigration to that ecosystem (Fig. 1B). For example, semelparous anadromous fish, such as Pacific salmon, are usually a net sink for the marine ecosystem in which they achieve most of their growth, but usually are a net source of nutrients to the freshwater ecosystems into which they migrate (Janetski et al. 2009). "Emigration" also can include harvest by humans, which represents a large nutrient outflux when harvest rates are high (Maranger et al. 2008). If emigration (including harvest) exceeds immigration, while growth plus reproduction balances mortality, fish biomass will decrease over time, making fish a sink because emigration represents a net loss of nutrients from the ecosystem. This example underscores the idea that sink strength cannot be inferred solely on the basis of nutrient pool size, or even by the net change in pool size.

Finally, animals can be an ecosystem-level sink if nutrients in dead individuals are not available to other organisms, but instead are sequestered long term in a recalcitrant form (Fig. 1C). This can be viewed as a special facet of nutrient sequestration into the animal pool (the first example), except in this case nutrients are stored in carcasses instead of living individuals. There is debate as to how quickly nutrients are mineralized from fish carcasses, especially P from P-rich bones and scales 

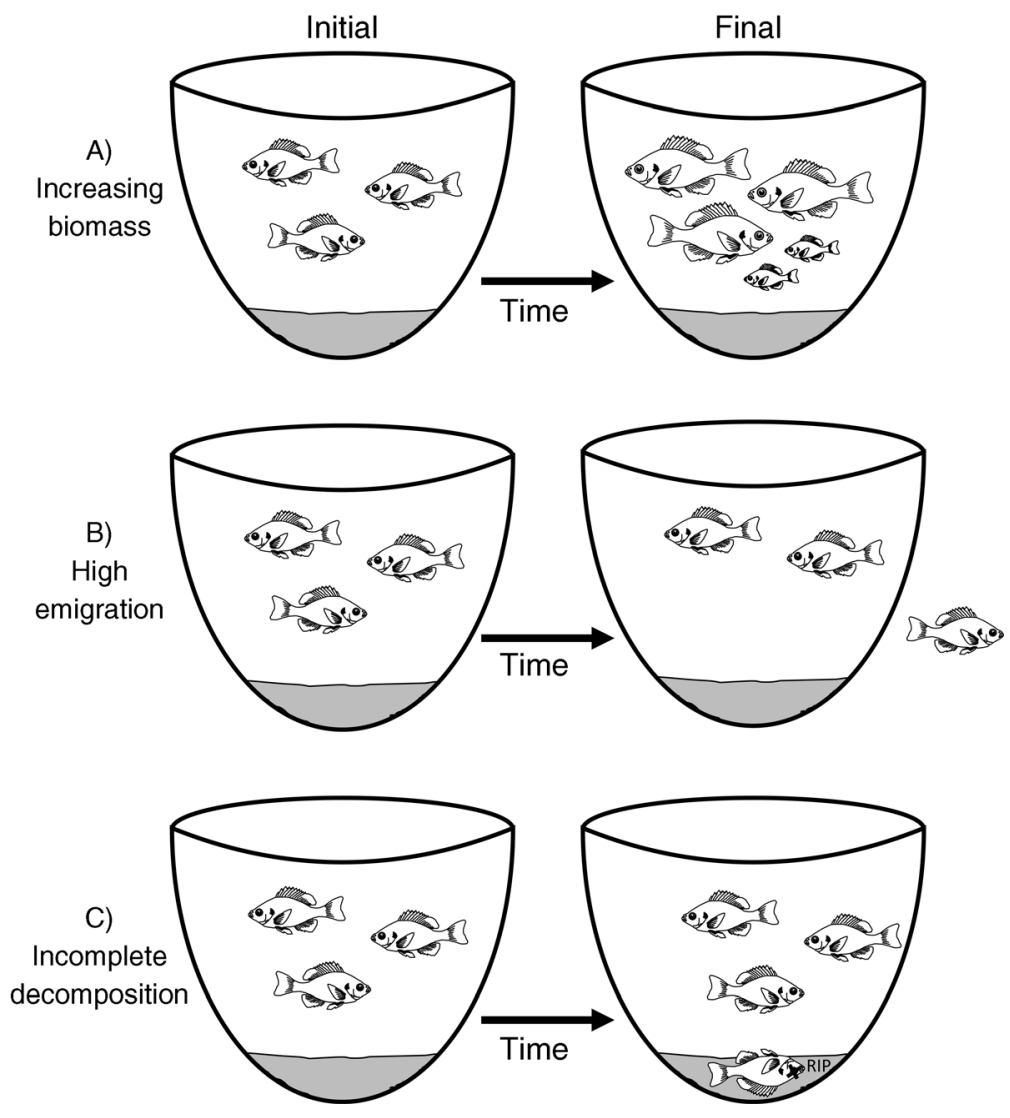

FIG. 1. Three general ways by which fish are ecosystem-level sinks for nutrients: (A) fish biomass increases over time via growth and reproduction, resulting in a net sequestration of nutrients in fish biomass; (B) emigration exceeds immigration, resulting in a net loss of fish-bound nutrients from the ecosystem; (C) dead fish do not completely decompose, and therefore some nutrients remain sequestered in carcasses.

(Schenau and De Lange 2000, Chidami and Amyot 2008, Premke et al. 2010).

Animals can also be nutrient sinks for specific habitats, even when they are not ecosystem-level sinks. For example, if fish consume benthic food resources and excrete nutrients into the water, they may be a sink for benthic nutrients but a source to the water column, regardless of any change in their biomass. The extent to which fish are sinks (i.e., "sink strength") for particular habitats can only be evaluated with quantitative data on where individuals feed; how they allocate nutrients to growth, feces, and excretion; immigration, emigration (including harvesting), and mortality rates; and the fate of nutrients post mortem. If carcass nutrients are stored long term in sediments, they are an ecosystem-level sink. If carcasses completely decompose, the remineralized $\mathrm{P}$ may be released into the water or used by benthic organisms. The sink strength of fish for benthic vs. water column habitats will thus depend on the origin of nutrients stored in fish tissues, what proportion of carcass nutrients is mineralized, and where mineralized nutrients become available.

\section{A Simple Model}

\section{Model structure}

We developed a simple model to investigate the potential role of fish as nutrient sources or sinks (Fig. 2). The model was used to estimate P fluxes to and from a fish assemblage feeding on invertebrates in a typical, moderately productive lake, but it could be modified for any ecosystem. Our model ecosystem contains four $\mathrm{P}$ pools: water column, benthos, live fish, and dead fish. We considered dead fish separately from other benthic $P$ because some carcass $\mathrm{P}$ may be unavailable to other organisms and because we wanted to explicitly evaluate the role of carcasses in creating a P sink. Modeled fluxes included consumption by fish from both benthic and water column prey; growth, egestion, excretion, immigration, and emigration by fish; and mineralization from fish carcasses (Fig. 2). "Growth" can be considered to include somatic growth as well reproduction.

We explored 16 model scenarios in a $2 \times 8$ factorial design. One factor varied the fate of excreted and mineralized P (Fig. 2), and had two states. In Pelagic uptake only scenarios, we assumed that $100 \%$ of 


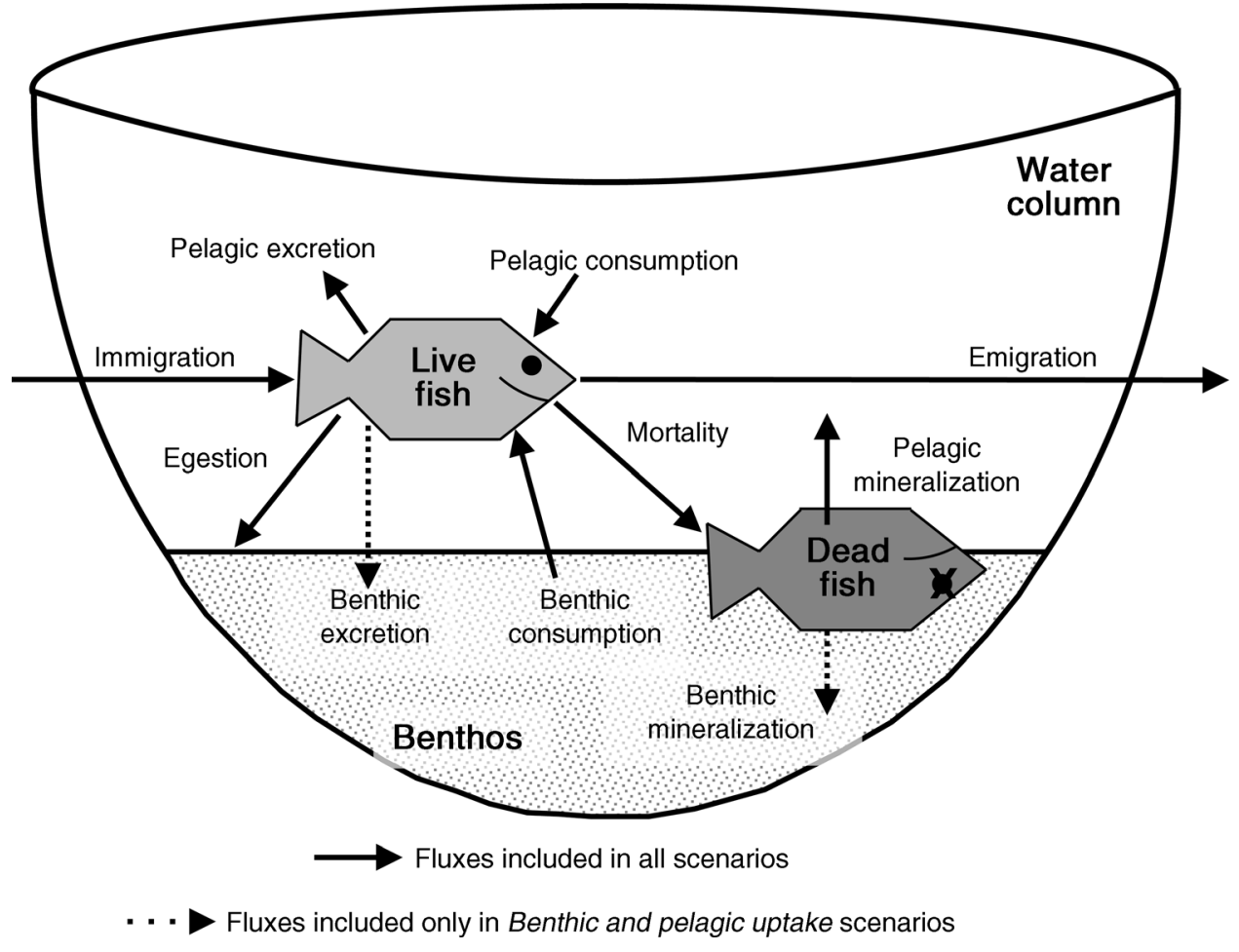

FIG. 2. Schematic diagram of the model for evaluating whether fish are nutrient sources or sinks. The model ecosystem has four pools: water column, benthos, live fish, and dead fish (in bold and italics). Arrows indicate fluxes of nutrients between pools, as well as immigration to and emigration from the ecosystem.

mineralized and excreted $\mathrm{P}$ was taken up by water column organisms (phytoplankton or pelagic bacteria). In Benthic and pelagic uptake scenarios, $64 \%$ of mineralized and excreted $\mathrm{P}$ was taken up by pelagic organisms and $36 \%$ by benthic primary producers and bacteria (Fig. 2). These percentages reflect the observation that on average $36 \%$ of lake primary production occurs in the benthos (Vander Zanden et al. 2011). To some extent these two scenarios reflect hypothesized differences in deep vs. shallow lakes. In deep lakes, most decomposition of fish carcasses probably occurs in profundal depths, where it is too dark for benthic primary production (Chidami and Amyot 2008). In this case most mineralized and excreted $\mathrm{P}$ is probably taken up by phytoplankton (although $\mathrm{P}$ mineralized in summer may not be accessible until fall turnover). In contrast, in shallow lakes a significant proportion of excretion and carcass decomposition probably occurs in shallow areas where benthic producers can take up released $\mathrm{P}$.

The other "factor" in our simulations was a set of eight scenarios varying the magnitudes of the flux rates shown in Fig. 2. We varied diet (proportion of consumption from the benthos vs. the water column), mineralization rate (proportion of carcass $\mathrm{P}$ mineralized vs. remaining in the dead fish pool), emigration rate, and net change in fish biomass. Each variation was done under both Pelagic uptake only and Benthic and pelagic uptake conditions, generating the $2 \times 8$ factorial design.

We evaluated whether fish are nutrient sinks or sources at both the ecosystem level and the habitat level (benthos or water column). There are several reasons for considering fish as habitat-specific sinks or sources. Benthic and water column habitats support different assemblages of primary producers, invertebrates, and to some extent fish. In addition, nutrients stored in benthos may contribute to a clear-water state, whereas nutrient fluxes to the water column can favor a turbid state (Scheffer et al. 1993). Thus, the relative magnitude of nutrient fluxes to and from these habitats is important. Furthermore, fish can mediate nutrient fluxes between the two habitats by feeding in both habitats (Vander Zanden et al. 2011), excreting benthic-derived nutrients into the water column (Vanni et al. 2006), and moving between habitats (Vanni 2002).

We consider $\mathrm{P}$ accumulating in fish biomass (live or dead) or leaving the lake in emigrating fish to represent ecosystem-level P sinks (Figs. 1 and 2), because in either case this $\mathrm{P}$ is unavailable to other lake biota. We recognize that live fish are eaten by piscivores. However, much of the $\mathrm{P}$ consumed by piscivorous fish would remain in the fish pool, and we assume that $\mathrm{P}$ consumed by piscivorous birds and mammals is either a negligible flux or is transported out of the lake. In all of these cases, $\mathrm{P}$ consumed by piscivores would still represent a 
sink for the rest of the lake ecosystem. Thus, in our 16 scenarios we assume no piscivory, and all dead fish were assumed to sink to the sediments. However, we explore some consequences of piscivory in additional simulations; see Discussion. We assumed that all egested $\mathrm{P}$ was deposited in the benthos as feces (Fig. 2).

Net P flux to the water column was calculated as [pelagic excretion + pelagic mineralization - pelagic consumption] (Fig. 2); positive values mean that fish are a nutrient source to the water column, while negative values mean that fish are a sink for water column P. Similarly, net flux to the benthos was obtained as [egestion + benthic excretion + benthic mineralization benthic consumption], although in the Pelagic uptake only scenarios benthic mineralization and benthic excretion fluxes were zero (Fig. 2). Net flux to the live fish pool is equal to [growth + immigration - mortality - emigration] (note that growth = consumption egestion - excretion), and net flux to dead fish pool is equal to [mortality - pelagic mineralization - benthic mineralization].

We first estimated fluxes through an individual fish and scaled these to the ecosystem level. To estimate individual fish consumption, we assumed a gross growth efficiency of 0.15 based on wet mass $\left(\mathrm{GGE}_{\mathrm{W}}\right.$, i.e., growth divided by consumption) and a wet mass-specific growth rate of $0.01 \mathrm{~g} \cdot \mathrm{g}^{-1} \cdot \mathrm{d}^{-1}$, both moderate values (Schindler and Eby 1997). For simplicity, we simulated fluxes for just one size class ( $10 \mathrm{~g}$ wet mass); thus growth rate for an individual fish was $0.1 \mathrm{~g}$ wet mass/d. Consumption rate was then calculated as growth rate divided by $\mathrm{GGE}_{\mathrm{W}}$, i.e., consumption rate was 0.667 $\mathrm{g} \cdot \mathrm{fish}^{-1} \cdot \mathrm{d}^{-1}$, equal to a daily consumption rate of $6.67 \%$ of fish wet mass (also a moderate rate for a $10 \mathrm{-g}$ fish [Kitchell et al. 1977]). To convert consumption and growth from wet mass to $\mathrm{P}$, we assumed that fish and their invertebrate prey have $\mathrm{P}$ contents of 0.005 and $0.0017 \mathrm{~g} \mathrm{P} /$ (g wet mass), respectively (Schindler and Eby 1997). P consumed by fish was then allocated to egestion, growth, or excretion. $\mathrm{P}$ allocated to growth was obtained as growth in wet mass times fish P content, i.e., fish were assumed to be stoichiometrically homeostatic. We assumed a $\mathrm{P}$ assimilation efficiency ( $\mathrm{P}$ assimilated/P consumed) of 0.72 (Schindler and Eby 1997). Thus $P$ egestion is $P$ consumption $\times 0.28$, and $P$ excretion is [( $\mathrm{P}$ consumption $\times 0.72)-\mathrm{P}$ growth]. Thus, $44 \%$ of consumed $\mathrm{P}$ was allocated to growth, i.e., gross growth efficiency for $\mathrm{P}\left(\mathrm{GGE}_{\mathrm{P}}\right)$ was 0.44 , and $\mathrm{P}$ egestion and excretion each accounted for $28 \%$ of $\mathrm{P}$ consumed. There are very few data on $\mathrm{P}$ allocation for fish populations in the field, but a $\mathrm{GGE}_{\mathrm{P}}$ of $44 \%$ is within the range estimated for bluegill sunfish, a common temperate fish in North America (Torres and Vanni 2007). To scale individual rates to the population level, we assumed a fish population density of $1 \mathrm{fish} / \mathrm{m}^{2}$. Given a mean wet mass of $10 \mathrm{~g}$, fish biomass was thus $100 \mathrm{~kg}$ / ha, typical of a moderately productive lake (Downing et al. 1990). In all scenarios, the total ecosystem pool of $P$ was held constant.

We started with Baseline scenarios, in which fish consumed $57 \%$ and $43 \%$ of their P from the benthos and water column, respectively, equal to mean percentages for energy consumption by fish populations from a recent synthesis (Vander Zanden et al. 2011). We assumed that live fish biomass did not change over time, mortality equaled growth, and immigration equaled emigration. Immigration and emigration $\mathrm{P}$ fluxes were each $12.5 \%$ of total fish $\mathrm{P}$ consumption. We also assumed that all fish carcass $\mathrm{P}$ was mineralized during the simulation period.

\section{Model results}

In the two Baseline scenarios, fish were a net $\mathrm{P}$ source to the water column and a sink of equal magnitude for benthic P (Fig. 3A). This occurs because fish consume more $\mathrm{P}$ from benthos than from the water column, growth is balanced by mortality, and all carcass $\mathrm{P}$ is mineralized. Within the two Baseline scenarios, net fluxes from the benthos and to the water column were much lower with Benthic and pelagic uptake than with Pelagic uptake only. At the ecosystem (lake) level, fish were neither a $\mathrm{P}$ source nor sink under either uptake scenario.

In subsequent simulations, we varied the proportion of $\mathrm{P}$ consumed from the water column vs. benthos, immigration and emigration rates, and carcass mineralization rates. In the Increasing biomass scenarios, mortality was equal to $50 \%$ of growth, so the biomass of live fish increased. As in the Baseline scenarios, all $\mathrm{P}$ entering the dead fish pool was mineralized, and all other fluxes were the same as in the Baseline scenarios. Mean fish biomass was also the same as in the Baseline scenarios, even though biomass increased over time. In both Increasing biomass scenarios, fish were a sink for benthic P (Fig. 3B). In contrast, fish were a source of $\mathrm{P}$ to the water column with Pelagic uptake only, but were a sink for water column P with Benthic and pelagic uptake. In both cases, P accumulated in the live fish pool, proportionally reducing $\mathrm{P}$ flux to the dead fish pool and thus $\mathrm{P}$ mineralization rate. Fish are $\mathrm{P}$ sinks at the ecosystem level under both Increasing biomass scenarios because $\mathrm{P}$ accruing in live fish is unavailable to other biota, despite remaining in the lake.

In the High emigration scenarios, immigration rate was the same as in the Baseline, but emigration rate was doubled. Thus, migration imparted a net flux of $\mathrm{P}$ out of the ecosystem. To compensate for increased emigration, mortality was reduced by an equivalent flux (because of this, total net flux into the live fish pool was zero). All other fluxes were the same as in the Baseline scenarios. With Pelagic uptake only, net flux from benthos was the same as in the previous two scenarios, and fish were a source of $\mathrm{P}$ to the water column intermediate between that of the Baseline and Increasing biomass scenarios (Fig. 3C). With Benthic and pelagic uptake, fish were also 


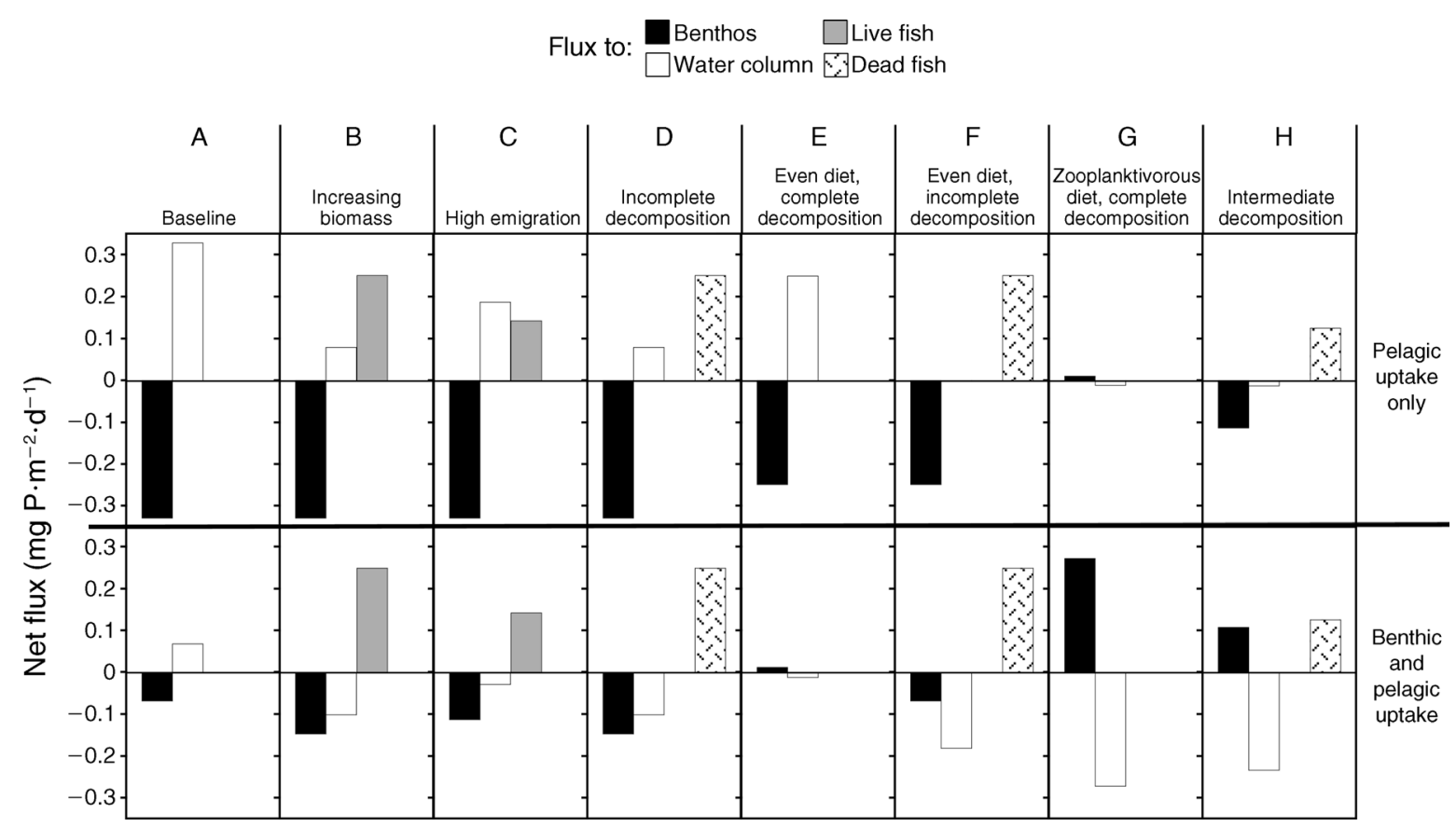

FIG. 3. Net P fluxes from the 16 scenarios. For net fluxes to the water column and benthos, positive values mean that fish were a net $\mathrm{P}$ source to that habitat (inputs exceeded outputs), while negative values mean that fish were a net $\mathrm{P}$ sink for that habitat (outputs exceeded inputs). Fluxes to live or dead fish are shown as positive values and represent ecosystem-level sinks. Note that, although we show a net flux to live fish in the High emigration scenario, this is actually the P flux out of the ecosystem via emigration.

an intermediate benthic sink, and a small sink for water column P. Fish are net sinks at the ecosystem level because the emigration of fish takes $\mathrm{P}$ out of the ecosystem under both uptake scenarios.

In the Incomplete decomposition scenario, we reduced total carcass mineralization rate to $50 \%$ of the carcass P pool, while keeping all other fluxes the same as in the Baseline. With Pelagic uptake only, fish were once again a sink for benthic $\mathrm{P}$ and a $\mathrm{P}$ source to the water column, but with Benthic and pelagic uptake fish were $\mathrm{P}$ sinks for both habitats (Fig. 3D). Within an uptake scenario, net fluxes of $\mathrm{P}$ to the water column or to the benthos were the same as in the Increasing biomass scenario (Fig. 3B). This is because mineralization flux was the same as in the Increasing biomass scenarios, the difference being that $\mathrm{P}$ accumulated in dead fish in the Incomplete decomposition scenario but in live fish in the Increasing biomass scenario. Fish are ecosystem-level sinks because $\mathrm{P}$ accumulating in carcasses is unavailable to other biota.

The next several scenarios examined variation in fish diets. We varied the proportion of $\mathrm{P}$ derived from water column prey (zooplankton) from $0 \%$ to $100 \%$ (with a corresponding reverse gradient in benthic consumption), at both high (100\%) and low (50\%) mineralization, and under both uptake scenarios. All other fluxes were equal to those in the Baseline. These simulations showed that fish are more apt to be water column P sinks when they feed heavily on zooplankton, but total mineralization rate and uptake pathways influence the extent to which fish are sources or sinks. For example, when all carcass $\mathrm{P}$ is mineralized, there is Pelagic uptake only, and diet is balanced between habitats (zooplankton and benthos each contribute $50 \%$ to $\mathrm{P}$ consumption), fish are a sink for benthic $\mathrm{P}$ and a source for water column $\mathrm{P}$ (Even diet/complete decomposition scenario; Fig. 3E). However, under the same conditions of $100 \%$ mineralization rate and an even diet, but with Benthic and pelagic uptake, fish were a slight $\mathrm{P}$ source to the benthos and a slight sink for water column P. With Pelagic uptake only and a balanced diet, but with mineralization rate equal to $50 \%$ (Even diet/incomplete decomposition scenario), fish were again a net sink for benthic $\mathrm{P}$ but were basically neutral with respect to water column P, i.e., the net flux between fish and the water column was essentially zero (Fig. 3F). The dead fish pool accumulated $\mathrm{P}$ at a rate equal to the net benthic sink. With Benthic and pelagic uptake, a balanced diet, and a 50\% mineralization rate, fish were net sinks for both habitats. Under the Even diet/incomplete decomposition scenarios, fish act as a P sink at the ecosystem level, regardless of uptake scenario (Fig. 3F).

Additional simulations show that the point along the consumption gradient at which fish switch from a source to a sink for the water column depends on mineralization rate and uptake scenario (Fig. 4). At high mineralization $(100 \%)$ and with Pelagic uptake only, fish must consume $\geq 73 \%$ of their $\mathrm{P}$ from the water 


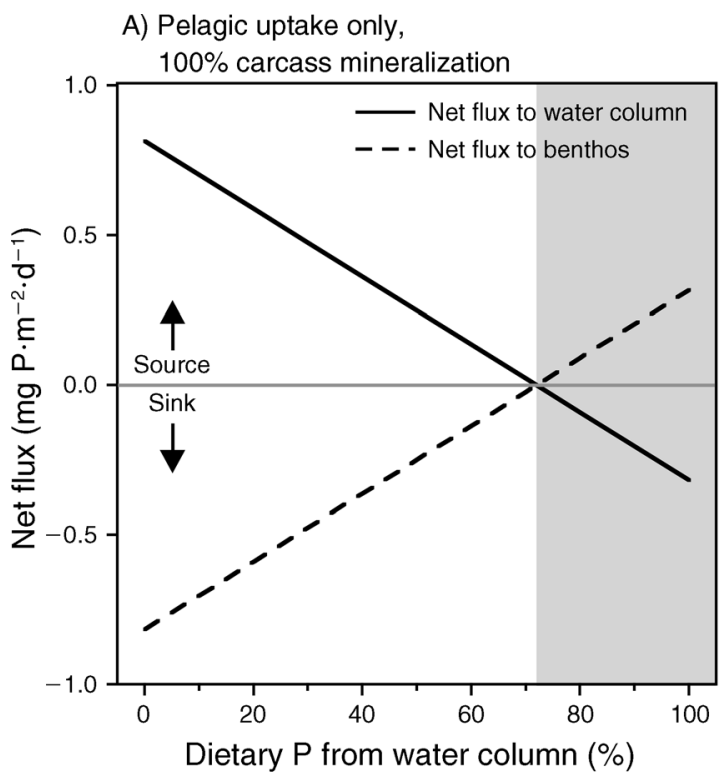

B) Pelagic uptake only, $50 \%$ carcass mineralization

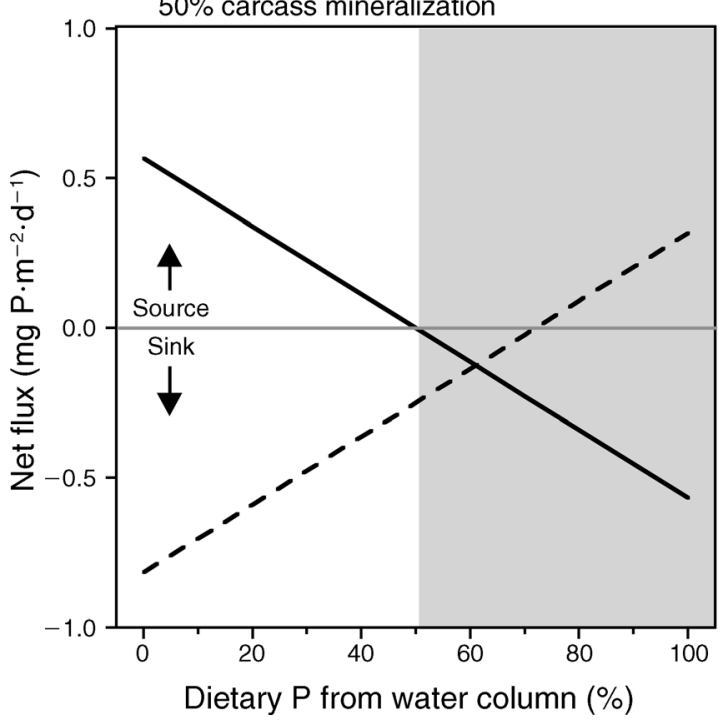

C) Pelagic and benthic uptake, $100 \%$ carcass mineralization

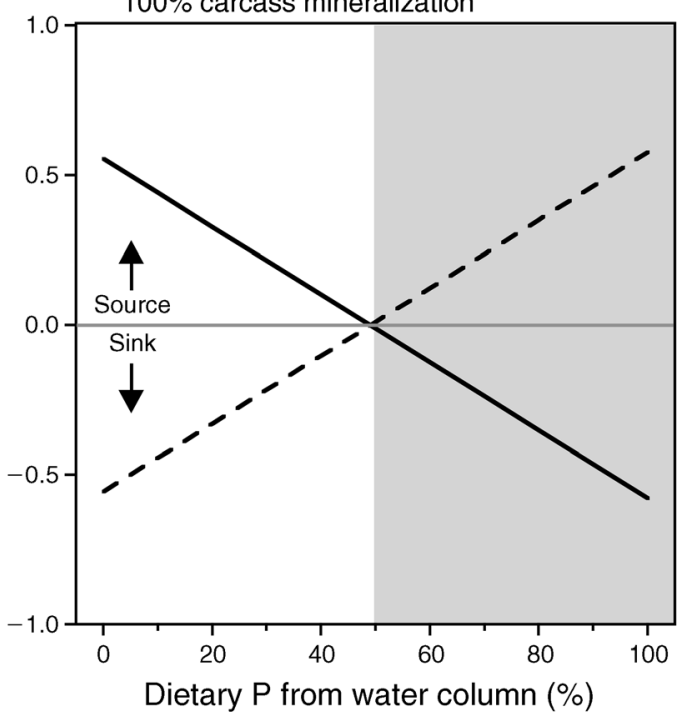

D) Pelagic and benthic uptake, $50 \%$ carcass mineralization

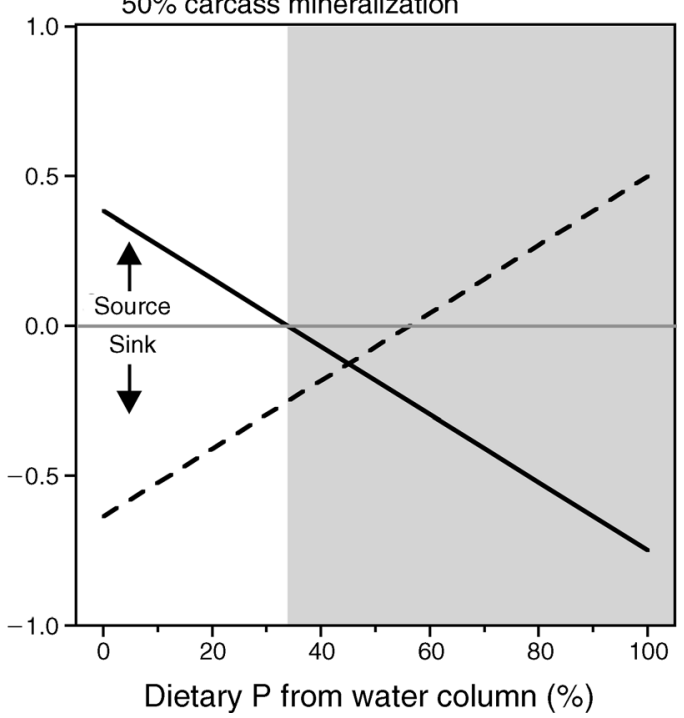

FIG. 4. The relationship between the percentage of dietary $\mathrm{P}$ fish obtain from the water column vs. net $\mathrm{P}$ flux to benthic and water column habitats, at two different carcass $\mathrm{P}$ mineralization rates and with the two different uptake scenarios. The shaded region indicates the range of diet conditions (percentage of dietary P from the water column) under which fish are net $\mathrm{P}$ sinks for the water column.

column to be net sinks for water column P (Fig. 4A). We refer to this as the Zooplanktivorous diet, complete decomposition scenario (Fig. 3G). With Pelagic uptake only and a mineralization rate of $50 \%$, fish are sinks for water column $\mathrm{P}$ if they consume $>50 \%$ of their $\mathrm{P}$ from the water column (Fig. 4B). Similarly, with Benthic and pelagic uptake and $100 \%$ mineralization, fish are sinks for water column $\mathrm{P}$ if they consume $>50 \%$ of their $\mathrm{P}$ from the water column (Fig. 4C). Finally, with Benthic and pelagic uptake and $50 \%$ mineralization, fish are sinks for water column $\mathrm{P}$ if they consume $>35 \%$ of their $\mathrm{P}$ from the water column (Fig. 4D).

Under the Zooplanktivorous diet/complete decomposition scenario with Benthic and pelagic uptake, fish are a large sink for water column $\mathrm{P}$ and a large $\mathrm{P}$ source to the benthos (Fig. 3G). Note that the source and sink strengths under these conditions are much stronger than in the Zooplanktivorous diet/complete decomposition scenario with Pelagic uptake only (Fig. 3G).

Finally, we used an intermediate mineralization rate, $75 \%$ of fish mortality, with all other fluxes equal to those 
in the Baseline scenarios. Then we iteratively increased proportional water column $\mathrm{P}$ consumption until fish were a net sink for water column $\mathrm{P}$ with Pelagic uptake only. Under this scenario (Intermediate decomposition), fish were a sink for water column nutrients when $>61 \%$ of their P consumption was from the water column (Fig. $3 \mathrm{H})$. Fish were an even greater sink for benthic nutrients, due to accumulation of $\mathrm{P}$ in the dead fish pool. With the same diet proportions (61\% from the water column) and total mineralization rate $(75 \%)$, but with Benthic and pelagic uptake, fish were a larger sink for water column $\mathrm{P}$, and for $\mathrm{P}$ sources to the benthos (Fig. 3H).

In these simulations, ecosystem-level sink strength was not affected by $\mathrm{P}$ uptake scenario, i.e., for a given Pelagic uptake only scenario sink strength was the same in the corresponding Benthic and pelagic uptake scenario (Fig. 3). This is because the uptake scenarios differ only in the habitat to which excreted and mineralized $\mathrm{P}$ is delivered, and not in net fluxes to live and dead fish.

\section{DisCusSION \\ When are fish ecosystem- or habitat-level sources or sinks?}

In our simulations, fish were $\mathrm{P}$ sinks at the ecosystem level when their biomass increased, emigration rates were high, or mineralization of carcasses was $<100 \%$. Among these possibilities, incomplete mineralization may be the most common means by which fish are ecosystem-level sinks; this possibility is discussed thoroughly below. Increasing biomass at the assemblage scale is not likely to be sustained long term, so this mechanism is probably rare overall but may be important seasonally or after fish kills. The general importance of emigration as a nutrient sink is hard to evaluate because fish display various migration patterns and quantitative migration rates are rarely known (Flecker et al. 2010). Harvesting, a special case of emigration, can be a substantial flux. Maranger et al. (2008) showed that harvest of marine fish is a significant flux of $\mathrm{N}$ (and presumably $\mathrm{P}$ ) from ocean to land, returning $\sim 20 \%$ of $\mathrm{N}$ inputs from fertilizer runoff. Many marine and freshwater fish populations have been harvested to a fraction of preharvest biomass (Myers and Worm 2003, Allan et al. 2005). This suggests that harvesting can generally be a large nutrient sink, but this has not been explicitly evaluated for most ecosystems. Also, at the ecosystem scale the removal of $\mathrm{P}$ via harvesting may be offset by increased anthropogenic $\mathrm{P}$ loading from runoff. Thus, harvesting may be an important nutrient loss in many ecosystems, but the net effect in the context of whole-ecosystem nutrient budgets is difficult to evaluate given the lack of information on flux rates.

Lake managers have also developed targeted harvesting regimes for planktivorous or benthivorous fish, referred to as food web biomanipulation (Hansson et al. 1998), which are also likely to affect how fish act as nutrient sources or sinks. Removal of these fish takes nutrients from the ecosystem and may reduce nutrient flux from the benthos to water by reducing fish-mediated bioturbation and/or excretion of benthic-derived nutrients. For example, gizzard shad (Dorosoma cepedianum) are purposely being removed from Florida lakes to reduce $\mathrm{P}$ pools and fluxes to the water (Catalano et al. 2010, Schaus et al. 2010). These real-world management efforts exemplify the importance of emigration, and especially harvest, in mediating ecosystem sink strength.

Our simulations suggest that fish are often sinks for a particular habitat, even when they are not ecosystemlevel sinks. Fish were net $\mathrm{P}$ sinks for benthic nutrients in most scenarios, and were rarely net $\mathrm{P}$ sources to the benthos; in contrast they were nearly equally likely to be net sources or sinks to the water column, considering all scenarios (Fig. 3). Fish are more likely to be sinks for the water column when their diets are highly zooplanktivorous, when carcasses do not fully mineralize, and when there is active benthic uptake of $\mathrm{P}$ (Figs. 3 and 4). The "zooplanktivory threshold" (percentage of P consumed from the water column) above which fish are sinks for water column $\mathrm{P}$ is quite high ( $73 \%$ zooplanktivory) if carcass mineralization is complete and all mineralized $\mathrm{P}$ is returned to the water column, but is much lower (35\%) if only half of carcass $\mathrm{P}$ is mineralized and there is benthic uptake of mineralized $\mathrm{P}$ (Fig. 4). At the assemblage or population level, fish consume more energy (and presumably nutrients) from the benthos than from the water column, and rarely rely on the water column for the majority of their diets. A recent synthesis of data from 75 lakes shows that fish assemblages obtain $>50 \%$ of their energy from the water column in only $\sim 30 \%$ of lakes, and obtain $>70 \%$ of their energy from the water column in $\sim 10 \%$ of lakes (Vander Zanden et al. 2011). Thus in most lakes, the feeding habits of fish should favor their functioning as $\mathrm{P}$ sinks for the benthos, but $\mathrm{P}$ sources to the water column. However, nearly all fish are zooplanktivorous as larvae, and sometimes for most of the first growing season, so young-of-year (YOY) fish could be $\mathrm{P}$ sinks. Thus, age structure and season will influence the overall extent to which fish populations or assemblages are sinks or sources to the water column.

Our simple model requires many assumptions, some more realistic than others. Future models and empirical studies will need to incorporate more complexity and additional factors that we could not consider within the scope of this paper. In the next sections, we discuss some of the limitations of our model, and additional factors that future studies should incorporate.

\section{The fate of fish carcasses}

Our simulations suggest that the sink strength of fish depends greatly on the fate of carcass $\mathrm{P}$, both the percentage of $\mathrm{P}$ mineralized and the fractions of this $\mathrm{P}$ taken up by benthic vs. pelagic producers. Low mineralization rates and a high proportion of benthic 
uptake both increase the chance that fish will be sinks for pelagic P. Unfortunately, there is little quantitative information available on either mineralization rates of fish carcasses or the relative importance of benthic vs. pelagic producers in using mineralized (or excreted) $\mathrm{P}$. Loss from whole carcasses is temperature dependent, as would be expected. For example, Kitchell et al. (1975) found that $\sim 60 \%$ of fish carcass $P$ was lost in 10 days in summer $\left(\sim 25^{\circ} \mathrm{C}\right)$ but only $\sim 20 \%$ was lost in winter over 20 days $\left(\sim 3^{\circ} \mathrm{C}\right)$. Because bones and scales contain the majority of fish $P$ (Hendrixson et al. 2007) and decompose more slowly than other tissues (e.g., Parmenter and Lamarra 1991), the fate of this P is critical. Fish bones and scales are present in the fossil record (Trueman and Martill 2002), so at least some carcass P is in a more or less permanent sink. However, studies in various ecosystems show that $<10 \%$ of bone and scale $\mathrm{P}$ is permanently buried if sediments are oxygenated, and even with hypoxia usually $<15 \%$ is permanently buried (Vallentyne 1960, Schenau and De Lange 2000).

Our Baseline mineralization rate, $100 \%$, should be seen as an upper limit. Considering the points discussed above, it is likely that the majority of fish carcass $\mathrm{P}$ (including that in bones and scales) is mineralized on fairly short time scales (weeks to months), but this is sure to vary among sites, seasons, and species. Further experimental and comparative studies are needed to constrain these rates, but the $50 \%$ mineralization rate we used in several scenarios is a reasonable lower bound for an annual period (Kitchell et al. 1975, Parmenter and Lamarra 1991). Furthermore, even if only $50 \%$ of $\mathrm{P}$ is mineralized in the same year that fish die, additional $\mathrm{P}$ will be slowly mineralized in subsequent years (Schenau and De Lange 2000). Our model did not explicitly separate within-year and delayed mineralization, but the rates we used can be viewed as their sum. Ultimately, the key point is that only permanently buried bone and scale $\mathrm{P}$ represents a true sink.

Although we focused on $\mathrm{P}$, freshwater and marine primary production is often nitrogen limited (Elser et al. 2007), and the role of fish in $\mathrm{N}$ cycling may differ from $\mathrm{P}$ cycling. Specifically, $\mathrm{N}$ is mineralized from fish carcasses much more rapidly than P. For example, trout carcasses lost $95 \%$ of their $\mathrm{N}$ over a 10 -month period during which they lost $60 \%$ of their P (Parmenter and Lamarra 1991). Bones and scales contain virtually no N. Thus, fish are much less likely to be $\mathrm{N}$ sinks than $\mathrm{P}$ sinks. Indeed, under conditions where carcasses are an important $\mathrm{P}$ sink, the storage of nutrients in carcasses may have important effects on ecosystem N:P ratios, with subsequent effects on primary producer nutrient limitation and species composition (Sterner and Elser 2002).

\section{More realistic food webs}

Our model includes only one size class, but agestructure variation is likely to influence how fish act as nutrient sinks or sources. In particular, YOY fish are more likely to be planktivorous and thus function as water column P sinks, compared to older fish. However, as long as age structure is consistent among scenarios, our general conclusions on the influences of mineralization, diet, and other variables should hold, even if source/sink strength magnitudes vary with age structure.

We also assumed that all mortality was due to "physiological death," i.e., we did not include piscivory. We also did not include consumption of carcasses by scavengers. Both piscivores and scavengers may store some of the $\mathrm{P}$ they consume, and in theory could represent additional $\mathrm{P}$ sinks. However, it seems unlikely that incorporating these food web members would substantially alter our findings. In most food webs, the biomass of most pools is likely at or near equilibrium across reasonable time frames for considering nutrient dynamics, or at least it is unlikely that the biomass of piscivores or scavengers will increase for long periods of time. Nevertheless, we explored the potential role of piscivory in mediating sink strength, by modifying the Baseline model with Pelagic uptake only. We considered the extreme case in which piscivorous fishes account for $100 \%$ of planktivorous/benthivorous fish mortality. We assumed that piscivore gross growth efficiency for wet mass was 0.15 (as for other fish), that piscivore biomass was constant (growth $=$ mortality), that all piscivore feces sank to the benthos, and that all piscivore carcass $P$ was remineralized. Under these conditions, piscivory reduced net $\mathrm{P}$ flux from the benthos, and to the water column, each by $\sim 43 \%$ relative to the Baseline model with Pelagic uptake only. While these flux reductions are substantial, we note that reducing mineralization rate to $50 \%$ (as in the Incomplete decomposition scenarios) reduced the net flux to the water column much more than piscivory, relative to the Baseline (Fig. 3). Furthermore, this simple piscivory scenario likely represents a maximal effect because piscivores will account for much less than $100 \%$ of the mortality of prey fish at the assemblage level (e.g., Hixon and Jones 2005, Denlinger et al. 2006).

Scavenging animals may rapidly consume fish carcasses, especially at shallow depths (Chidami and Amyot 2008, Janetski et al. 2009, Premke et al. 2010). However, as with piscivores, scavengers are unlikely to be a longterm ecosystem-level $\mathrm{P}$ via a long-term biomass increase. On the other hand, scavengers may be more likely than other animals to export nutrients from an ecosystem (e.g., birds or bears that feed on salmon carcasses). Clearly, chains of feeding interactions involving scavengers and piscivores need to be addressed in future sink/ source studies.

Consideration of the inclusion of piscivores and scavengers raises the issue of time scale, specifically how variation in pool residence time affects sink and source strengths. For example, scavengers or piscivores may temporarily be a sink for nutrients they consume, but eventually the nutrients in their bodies will have the same fates as those of the fish they consume, i.e., they 
will be mineralized at some point (or exported from the ecosystem). However, while the time scale over which body nutrients are mineralized is probably correlated with body size, the long-term fate of these nutrients is probably independent of body size. Nutrients in the biomass of long-lived species such as piscivorous fish will remineralize at relatively long time scales, nutrients in small fish and invertebrates will be mineralized at intermediate time scales, and microbial nutrients will be rapidly mineralized. However, assuming steady-state biomass, large animals are not any more likely to be ecosystem-level sinks than smaller organisms, unless it is more likely that their nutrients are sequestered permanently in carcasses. Thus, the fate of carcass $\mathrm{P}$ is potentially so important because it provides a mechanism for immobilization that violates the steady-state nutrient pool assumption.

\section{Environmental factors such as lake size and productivity}

The Pelagic uptake only vs. Benthic and pelagic uptake scenarios to some extent reflect hypothesized differences in deep vs. shallow lakes, as discussed previously. If the Pelagic uptake only scenario is more likely in deep lakes, fish may be more likely to be $\mathrm{P}$ sources to the water column in deep lakes, mainly because of reduced benthic nutrient uptake in these lakes. However, additional interactions and factors may also differ in shallow vs. deep lakes, and may counteract this effect. For example, fish may be more zooplanktivorous in deep lakes, and greater zooplanktivory may reduce the extent to which fish are $\mathrm{P}$ sources to the water column. We also assumed that all feces are deposited to the benthic pool, but some proportion is probably mineralized within the water column, and this proportion seems likely to be greater in deep ecosystems. In addition, some fecal $\mathrm{P}$ will be mineralized rapidly from surface sediments, and may be taken up by either pelagic or benthic primary producers. If fecal nutrients are mineralized either in the water column or in surface sediments, this would render fish more of a nutrient source to the water column habitat than our models estimate. The fate of fecal nutrients probably depends on lake size (especially depth), but the lack of data on these fluxes precludes us from investigating this further.

Variation in the nutrient contents of fishes themselves and their food items also may be important, and may vary with lake productivity and size. Fish consuming items low in $\mathrm{P}$ may be more likely to be $\mathrm{P}$ sinks because they must accumulate a relatively high fraction of ingested P. For example, P-rich catfish consuming low$\mathrm{P}$ algae appear to show P-limited growth (Hood et al. 2005), meaning that they will sequester as much dietary $\mathrm{P}$ as possible and excrete $\mathrm{P}$ at low rates. In contrast, carnivorous fishes are likely to be energy limited, giving them excess $P$ to recycle (Schindler and Eby 1997). Thus, $\mathrm{P}$ cycling rate will be positively related to dietary $\mathrm{P}$ content and negatively related to fish body $\mathrm{P}$ content
(Sterner and Elser 2002); thus, fish are more likely to be $\mathrm{P}$ sinks when they eat detritus and plant material, and when they have particularly high body $\mathrm{P}$.

Dietary nutrient content may be especially interesting in the context of variation among lakes in productivity (nutrient supply) and benthic vs. planktonic dependence of food webs. High nutrient supply rates generally boost algal $\mathrm{P}$ content, which leads to excretion or egestion of a greater fraction of ingested $\mathrm{P}$ by herbivores than if nutrient supply is low (Sterner and Elser 2002). Thus, the productivity of high-nutrient lakes may engender elevated nutrient regeneration rates. Similarly, differences in nutrient content of benthic vs. water column prey could exacerbate the habitat-level role of fishes as sources vs. sinks. Though zooplankton and benthic invertebrates overlap broadly in tissue nutrient content (Elser et al. 2000, Cross et al. 2003), it is plausible that the P content of Daphnia consumed by zooplanktivorous fishes in the water column exceeds that of insect larvae eaten by benthivorous fishes. In this scenario (which could be reversed if different invertebrate prey taxa are considered), the proportion of $\mathrm{P}$ consumed from the water column will be higher than the proportion of energy consumed from the water column. This could render fishes more likely to be sinks for water column $\mathrm{P}$, because they export pelagic-derived $\mathrm{P}$ to the benthos via feces and mortality. Between-habitat differences in prey $\mathrm{P}$ content would violate our model assumptions that the fractional contributions of benthos and water column habitats to fish $\mathrm{P}$ intake equal those for energy consumption. Future investigations should examine this assumption, but the predicted effects should reflect the imbalance between dietary $\mathrm{P}$ from different habitats.

Our models do not include the indirect effects of fish on nutrient cycling, which may be quite important relative to direct effects. (We define direct effects as nutrient fluxes through fish.) For example, fish often have strong top-down effects, which can affect excretion rates of prey fishes and invertebrates (e.g., Schindler et al. 1993) and other fundamental ecosystem processes (Vanni 2002, Flecker et al. 2010). In nature, indirect effects of fish on nutrient cycling often exceed their direct effects, and indirect effects might determine the net sink strength of fish. Future models need to incorporate both sets of pathways.

\section{Conclusions}

Kitchell et al. (1975, 1979) recognized decades ago that the use, storage, and release of nutrients by fish can affect nutrient cycles in complex ways. Although they pointed out that fish represent a large, highly concentrated, and persistent pool of nutrients, they also suggested that fish decomposition represents a longterm and steady supply of nutrients that can sustain productivity. Thus, they did not view fish as long-term sinks. Rather, they [and Steele (1974)] argued that fish can have a function similar to trees in a forest, 
representing a large nutrient pool that can be a source for periods exceeding one growing season. More recently, others have concluded that because fish represent a large pool size with a relatively slow turnover rate, they are nutrient sinks (Griffiths 2006, Sereda et al. 2008, Sereda and Hudson 2010). However, as we show here and as Kitchell et al. (1975) originally inferred, a large pool size does not necessarily equate to a sink. Rather, the sink strength of fish assemblages depends on the spatial scale of interest (habitat or ecosystem level) as well as feeding habits, temporal changes in biomass, migration, and harvest rates, and especially the fate of carcasses. Nor can the importance of time scale be overemphasized; for organisms with short nutrient residence time (e.g., bacteria), relatively long-lived fishes may appear to be sinks, whereas nutrient flux through fishes may be rapid compared to sediment nutrient regeneration or interannual variation in watershed nutrient loads. Given that there is no "correct" time scale for assessing ecosystem nutrient dynamics, debate over whether fishes are nutrient sinks is likely to continue.

Many studies over the past few decades have investigated various aspects of nutrient cycling by fish (Carpenter et al. 1992, Vanni 2002, Janetski et al. 2009). Yet few, if any, studies have approached this problem in the comprehensive way that is needed to fully understand the many ways in which fish (and other animals) modulate nutrient cycles. Given the ideas put forth by Kitchell et al. $(1975,1979)$ decades ago, this is quite surprising. We hope that the concepts and simple models presented in this paper will inspire and guide a more holistic approach that incorporates this complexity.

\section{ACKNOWLEDGMENTS}

We thank E. Mette, K. Downs, L. Ginger, N. Hayes, A. Showalter, and two anonymous reviewers for comments on an earlier draft. M. J. Vanni acknowledges support from an NSF OPUS award (DEB 0918993), G. Boros was supported by a postdoctoral fellowship from the Rosztoczy Foundation, and P. B. McIntire acknowledges funding from NSF (DEB1030242). We are indebted to Jim Kitchell for his pioneering work on nutrient cycling by fish, which influenced many of the ideas in this paper.

\section{Literature Cited}

Allan, J. D., R. Abell, J. Hogan, C. Ravenga, B. W. Taylor, R. L. Wellcome, and K. Winemiller. 2005. Overfishing of inland waters. BioScience 55:1041-1051.

Carpenter, S. R., K. L. Cottingham, and D. E. Schindler. 1992. Biotic feedbacks in lake phosphorus cycles. Trends in Ecology and Evolution 7:332-336.

Catalano, M. J., M. S. Allen, M. H. Schaus, D. G. Buck, and J. R. Beaver. 2010. Evaluating short-term effects of omnivorous fish removal on water quality and zooplankton at a subtropical lake. Hydrobiologia 655:159-169.

Chidami, S., and M. Amyot. 2008. Fish decomposition in boreal lakes and biogeochemical implications. Limnology and Oceanography 53:1988-1996.

Cross, W. F., J. P. Benstead, A. D. Rosemond, and J. Bruce Wallace. 2003. Consumer-resource stoichiometry in detritusbased streams. Ecology Letters 6:721-732.

Denlinger, J. C. S., R. S. Hale, and R. A. Stein. 2006. Seasonal consumptive demand and prey use by stocked saugeyes in
Ohio reservoirs. Transactions of the American Fisheries Society 135:12-27.

Downing, J. A., C. Plante, and S. Lalonde. 1990. Fish production correlated with primary productivity, not the morphoedaphic index. Canadian Journal of Fisheries and Aquatic Sciences 47:1929-1936.

Elser, J. J., M. E. S. Bracken, E. E. Cleland, D. S. Gruner, W. S. Harpole, H. Hillebrand, J. T. Ngai, E. W. Seabloom, J. B. Shurin, and J. E. Smith. 2007. Global analysis of nitrogen and phosphorus limitation of primary producers in freshwater, marine and terrestrial ecosystems. Ecology Letters 10: $1135-1142$.

Elser. J. J., et al. 2000. Nutritional constraints in terrestrial and freshwater food webs. Nature 408:578-580.

Estes, J. A., et al. 2011. Trophic downgrading of planet earth. Science 333:301-306.

Flecker, A. S., P. B. McIntyre, J. W. Moore, J. T. Anderson, B. W. Taylor, and R. O. Hall. 2010. Migratory fishes as material and process subsidies in riverine ecosystems. American Fisheries Society Symposium 73:559-592.

Frank, D. A. 2008. Ungulate and topographic control of nitrogen: phosphorus stoichiometry in a temperate grassland; soils, plants and mineralization rates. Oikos 117:591-601.

Griffiths, D. 2006. The direct contribution of fish to lake phosphorus cycles. Ecology of Freshwater Fish 15:86-95.

Grimm, N. B. 1988. Role of invertebrates in nitrogen dynamics of a desert stream. Ecology 69:1884-1893.

Hansson, L.-A., H. Annadotter, E. Bergman, S. F. Hamrin, E. Jeppesen, T. Kairesalo, E. Luokkanen, P. A. Nilsson, M. Sondergaard, and J. Strand. 1998. Biomanipulation as an application of food-chain theory: constraints, synthesis, and recommendations for temperate lakes. Ecosystems 1:558574.

Hendrixson, H. A., R. W. Sterner, and A. D. Kay. 2007. Elemental stoichiometry of freshwater fishes in relation to phylogeny, allometry and ecology. Journal of Fish Biology 70:121-140.

Hixon, M. A., and G. P. Jones. 2005. Competition, predation, and density-dependent mortality in demersal marine fishes. Ecology 86:2847-2859.

Hood, J. M., M. J. Vanni, and A. S. Flecker. 2005. Nutrient recycling by two phosphorus-rich grazing catfish: the potential for P-limitation of fish growth. Oecologia 146: 247-257.

Janetski, D. J., D. T. Chaloner, S. D. Tiegs, and G. A. Lamberti. 2009. Pacific salmon effects on stream ecosystems: a quantitative synthesis. Oecologia 159:583-595.

Kitchell, J. F., J. F. Koonce, and P. S. Tennis. 1975. Phosphorus flux through fishes. Internationale Vereinegung für theoretische und angewandte Limnologie, Verhandlungen 19:2478-2484.

Kitchell, J. F., R. V. Oneill, D. Webb, G. W. Gallepp, S. M. Bartell, J. F. Koonce, and B. S. Ausmus. 1979. Consumer regulation of nutrient cycling. BioScience 29:28-34.

Kitchell, J. F., D. J. Stewart, and D. Weininger. 1977. Applications of a bioenergetics model to yellow perch (Perca flavescens) and walleye (Stizostedion vitreum vitreum). Journal of the Fisheries Research Board of Canada 34:1922-1934.

Maranger, R., N. Caraco, J. Duhamel, and M. Amyot. 2008. Nitrogen transfer from sea to land via commercial fisheries. Nature Geoscience 1:111-113

McIntyre, P. B., A. S. Flecker, M. J. Vanni, J. M. Hood, B. W. Taylor, and S. A. Thomas. 2008. Fish distributions and nutrient cycling in streams: Can fish create biogeochemical hotspots? Ecology 89:2335-2346.

McNaughton, S. J., F. F. Banyikwa, and M. M. McNaughton. 1997. Promotion of the cycling of diet-enhancing nutrients by African grazers. Science 278:1798-1800.

Myers, R. A., and B. Worm. 2003. Rapid worldwide depletion of predatory fish communities. Nature 432:280-283. 
Parmenter, R. R., and V. A. Lamarra. 1991. Nutrient cycling in a fresh-water marsh-the decomposition of fish and waterfowl carrion. Limnology and Oceanography 36:976-987.

Premke, K., P. Fischer, M. Hempel, and K.-O. Rothhaupt. 2010. Ecological studies on the decomposition rate of fish carcasses by benthic organisms in the littoral zone of Lake Constance, Germany. Annales de Limnologie-International Journal of Limnology 46:1-12.

Schaus, M. H., W. Godwin, L. Battoe, M. Coveney, E. Lowe, R. Roth, C. Hawkins, M. Vindigni, C. Weinberg, and A. Zimmerman. 2010. Impact of the removal of gizzard shad (Dorosoma cepedianum) on nutrient cycles in Lake Apopka, Florida. Freshwater Biology 55:2401-2413.

Scheffer, M., S. H. Hosper, M.-L. Meijer, B. Moss, and E. Jeppesen. 1993. Alternative equilibria in shallow lakes. Trends in Ecology and Evolution 8:275-279.

Schenau, S. J., and G. J. De Lange. 2000. A novel chemical method to quantify fish debris in marine sediments. Limnology and Oceanography 45:963-971.

Schindler, D. E., and L. A. Eby. 1997. Stoichiometry of fishes and their prey: implications for nutrient recycling. Ecology 78:1816-1831.

Schindler, D. E., J. F. Kitchell, X. He, S. R. Carpenter, J. R. Hodgson, and K. L. Cottingham. 1993. Food-web structure and phosphorus cycling in lakes. Transactions of the American Fisheries Society 122:756-772.

Schmitz, O. J., D. Hawlena, and G. C. Trussell. 2010. Predator control of ecosystem nutrient dynamics. Ecology Letters 13: $1199-1209$.

Sereda, J. M., and J. J. Hudson. 2010. Comparative estimate of $P$ fluxes in lakes: a comment on "Fish decomposition in boreal lakes and biogeochemical implications" by Chidami and Amyot (2008). Limnology and Oceanography 55:463465.

Sereda, J. M., J. J. Hudson, W. D. Taylor, and E. Demers. 2008. Fish as sources and sinks of nutrients in lakes. Freshwater Biology 53:278-289.

Steele, J. H. 1974. The structure of marine ecosystems. Harvard University, Cambridge, Massachusetts, USA.

Sterner, R. W., and J. J. Elser. 2002. Ecological stoichiometry: the biology of elements from molecules to the biosphere. Princeton University, Princeton, New Jersey, USA.

Torres, L. E., and M. J. Vanni. 2007. Stoichiometry of nutrient excretion by fish: interspecific variation in a hypereutrophic lake. Oikos 116:259-270.

Trueman, C. N., and D. M. Martill. 2002. The long-term survival of bone: the role of bioerosion. Archaeometry 44: 371-382.

Vallentyne. J. R. 1960. On fish remains in lacustrine sediments. American Journal of Science 258-A:344-349.

Vander Zanden, M. J., Y. Vadeboncoeur, and S. Chandra. 2011. Fish reliance on littoral-benthic resources and the distribution of primary production in lakes. Ecosystems 14: 894-903.

Vanni, M. J. 2002. Nutrient cycling by animals in freshwater ecosystems. Annual Review of Ecology and Systematics 33: 341-370.

Vanni, M. J., A. M. Bowling, E. M. Dickman, R. S. Hale, K. A. Higgins, M. J. Horgan, L. B. Knoll, W. H. Renwick, and R. A. Stein. 2006. Nutrient cycling by fish supports relatively more primary production as lake productivity increases. Ecology 87:1696-1709.

Vitousek., P. M. 2004. Nutrient cycling and limitation: Hawai'i as a model system. Princeton University, Princeton, New Jersey, USA. 